\title{
Food Preferences and Dark-side Personality Traits
}

Adrian Furnham

Norwegian Business School (BI), Nydalveien, Olso, Norway.

Corresponding Author: Adrian Furnham, Norwegian Business School (BI), Nydalveien, Olso, Norway.

Received date: October 09, 2021; Accepted date: November 26, 2021; Published date: January 04, 2022

Citation: Adrian Furnham (2022) Food Preferences and Dark-side Personality Traits. Psychology and Mental Health Care, 6(1): DOI: $10.31579 / 2637-8892 / 148$

Copyright: ( ) 2022, Adrian Furnham, This is an open access article distributed under the Creative Commons Attribution License, which permits unrestricted use, distribution, and reproduction in any medium, provided the original work is properly cited.

\begin{abstract}
This study investigated the association between a variety of taste preferences and the Dark Triad personality traits. We noted over twenty studies that linked personality to taste/beverage preference and experience. In this study just under 200 participants completed a personality and food preference questionnaire. Results demonstrated that dark side traits accounted for around ten percent of the variance in tastes, including bitter and sweet as well as alcohol and coffee strength preferences. For a number of the taste preference measures sensation seeking and harm aversive personality traits were particularly influential in determining taste preferences. Limitations and directions for future research are discussed.
\end{abstract}

Keywords: taste preferences; dark side traits; power; sweet and sour

\section{Introduction}

Eating and drinking satisfies the basic human need of sustenance from consumption (Sagioglou \& Greitemeyer, 2016). Being able to distinguish and find essential nutrients and exclude potentially harmful items was critical for human's survival, especially hunter-gatherer communities for whom acquiring sufficient calories was a challenging reality (Bradbury, 2004; Reed, Tanaka \& McDaniel, 2006; Spence 2017). A natural craving for 'sweet' tastes usually ensures sufficient caloric uptake from food and drink sources high in sugar and carbohydrates, while the perception of 'salty' incentivises consumption of foods with sodium chloride, essential for metabolic processes. Salty foods are inherently attractive also because they signal protein (Bartoshuk, 1991). In contrast, the perception of 'sour' signals an item's acidity, a cue that it is unripe or has spoiled, and similarly the perception of 'bitter' highlights the possible presence of toxins or harmful compounds (Desor, Maller \& Andrews, 1975).

Taste partly dictates our food and drink preferences (Glanz et al., 1998). Neonates demonstrate a 'hard-wired' preference for sweet tastes, and an aversion to those which are bitter or sour (Steiner et al., 2001). However, as we develop into adulthood, a variety of preferences for different taste sensations are formed. These personal, idiosyncratic and 'acquired tastes' appear to be shaped by cultural and social factors (Higgs, 2015; Rozin, Haidt \& Fincher, 2009; Ulrich-Lai et al., 2010). They are also shaped by individual differences like personality. However, the relationship between personality traits and taste preference has received relatively little attention until recently (Ardebili, \& Rickertsen, 2020; Bedwell et al., 2019; Saliba, Wragg \& Richardson, 2009; Samat \& Seo, 2019ab). Most recent studies have also explored situational determinants of taste (Zushi et al, 2021).

Personality and Taste Preferences
There are various reasons to assume a link between personality and taste preference. Both the earlier Freudians and later psychometyricians linked food preferences to personality (Furnham, 2008). Thus it was argued that as a function of weaning two types of oral personalities arose: the orally optimistic and others orally pessimistic. Optimists find the mouth and all oral activities a source of pleasure (even eroticism): eating, drinking, talking, singing, smoking is a joy, as is playing wind instruments and kissing. On the other hand, oral pessimists use the mouth to spit venom, give biting comments, return ideas well chewed over. Oral pessimists like hot, biting food: a meat Madras, preserved ginger, sherbet. The gregarious oral optimists like rice pudding, milk, and mashed potato.

Personality trait psychologists sugested a greater preference for sweet tastes was found in individuals with greater prosocial personality traits (Meier et al., 2012), Agreeableness (Meier et al., 2012), Neuroticism (Keller \& Seigrist, 2015), and lower levels Openness (Saliba et al., 2009). Similarly, it has been found that highly disinhibited groups have a greater preference for sweet foods (Haynes, Lee \& Yeomans, 2003), in particular sweet chocolate (Lattimore \& Maxwell, 2004). Additionally, individuals with higher levels of trait Sensation-Seeking demonstrate dietary and taste preferences towards spicy foods (Byrnes \& Hayes, 2013), caffeinated beverages (Mattes, 1994) and alcoholic drinks (Magid, MacLean \& Colder, 2007). The relationship between sensation seeking and bitter taste could be attributed to simply seeking intense sensations regardless of valence. There is also a known relationship between sensation seeking and testosterone (Bègue, et al., 2015)

Similarly, the experience of taste appears to exert psychological effects upon the individual. For example, individuals subjected to a sweet taste experience subsequently report greater intention to help others (Meier et 
al., 2012), and decreased death anxiety (Hirshcberger \& Ein-Dor, 2005). Conversely people demonstrate harsher moral judgement (Eskine, Kacinik \& Prinz, 2011) and interpersonal hostility (Sagioglou \& Greitemeyer, 2014) following exposure to bitter tastes. Batra et al. (2017) found across three studies that those who typically consume spicy food exhibit higher levels of trait aggression.

In a very recent and important review, Esposito et al. (2021) noted many studies which showed that personality traits influenced dietary choices and the type of diet. Certain personality traits, such as Neuroticism and Alexithymia, were associated with unhealthy diet habuts: low consumption of fruit and vegtables, increased consumption of sugar and saturated fats. Further, they reported studies which show that personality seems to play a role in food selection and in the propensity to change diets.

\section{The Dark Side of Personality}

The above findings are consistent with the notion that individuals described as 'bitter' or 'sour' possess some negative personality trait (Meier et al., 2012); quite literally, they elicit the same negative response in individuals around them that an adverse or bitter taste would. Very few studies have expolored the possible relationship between dark side personality traits and taste preferences. In one study, the sensory liking for sweet and fat was negatively associated with histrionic personality traits (Mihaela \& Bianca (2018). However, Sagrioglou and Greitemeyer (2016) found that bitter taste preferences were positively correlated with Psychopathy, Everyday Sadism, Machiavellianism and Narcissism. Sour preferences were positively correlated with Everyday Sadism, and salty preferences were negatively correlated with Everyday Sadism. These four traits compromise a 'Dark tetrad' of negative personality traits (Chabrol et al., 2009), with the addition of 'Everyday Sadism' marking its difference to the predominant 'Dark Triad' model (Psychopathy, Machiavellianism and Narcissism) of hostile personality (Paulhus \& Williams, 2002).

This study has not been fully replicated (Waymire, 2017). More importantly, in a test of 78 individuals, Mahmut and Banzer (2020)

\begin{tabular}{|c|c|}
\hline Citation & Key Findings \\
\hline Rozin, Haidt \& Fincher (2009) & $\begin{array}{l}\text { Disgust to morally repugnant behaviour is a development from our physiological gustatory } \\
\text { responses to bitter tastes }\end{array}$ \\
\hline Ulrich-Lai et al. (2010) & Emotional stress is alleviated by physiological response to experiencing sweet tastes \\
\hline Saliba, Wragg \& Richardson (2009) & Sweet taste preferences are associated with greater impulsiveness but lower openness \\
\hline Kikuchi \& Watanabe (2000) & Sweet and salty taste preferences are associated with greater neuroticism \\
\hline $\begin{array}{l}\text { Meier, Moeller, Reimer-Peltz \& Robinson } \\
\text { (2012) }\end{array}$ & $\begin{array}{l}\text { Sweet taste preferences are associated with greater prosocial personality traits and } \\
\text { agreeableness }\end{array}$ \\
\hline Keller \& Siegrist (2015) & Sweet taste preferences are associated with greater neuroticism \\
\hline Haynes, Lee \& Yeomans (2003) & Sweet taste preferences are associated with greater disinhibition \\
\hline Lattimore \& Maxwell (2004) & Sweet taste preferences are associated with greater disinhibition \\
\hline Byrnes \& Hayes (2013) & Spicy taste preferences are associated with greater sensation-seeking \\
\hline Mattes (1994) & Caffeinated beverage preference is associated with greater sensation-seeking \\
\hline Magid, Maclean \& Colder (2007) & Alcoholic beverage preference is associated with is associated with greater sensation-seeking \\
\hline Eskine, Kacinik \& Prinz (2011) & Bitter taste experience is associated with increased harsh moral judgement \\
\hline Sagioglou \& Greitemeyer (2014) & Bitter taste experience is associated with increased interpersonal hostility \\
\hline
\end{tabular}

found contrary to previous findings, higher psychopathic traits were not associated with higher liking ratings for bitter stimuli, but instead higher disgust ratings of bitter stimuli. Also higher psychopathic traits were associated with higher taste intensity ratings, suggesting psychopathy may be associated with increased taste sensitivity. They argued that their findings suggest that the chemical senses may be another confirmatory method for differentiating those with low and high psychopathic traits.

In another recent and relevant study, Sariyska et al., (2019) showed higher scores on Machiavellianism, Narcissism and Psychopathy for the omnivores compared to vegans/vegetarians, though those effects got weaker or disappeared after the sex of participants was added to the model.

\section{The current study}

The existing body of research literature is summarised in Table 1. The existing research suggests a relationship between taste preferences and an individual's perceived ability to influence interpersonal relationships and an ability to exert control over others' attitudes, opinions and behaviours as well as their own (e.g Meier et al., 2012; Haynes et al., 2003; Byrnes \& Hayes, 2013). These are all manifestations of the individual's sense of power (Anderson, John \& Keltner, 2012). Additionally, sensation-seeking and risk-seeking traits are also conceptually and empirically linked to the individual's sense of power (Dholakia et al., 2006; Idson, Liberman \& Higgins, 2000; Hmielski \& Baron, 2008). As such, perceived power as a specific facet of personality appears to demonstrate a variety of relationships with taste preferences.

Based on the available evidence, this exploratory study attempts to address two primary research questions: Is there a relationship between personality individual difference measures, as manifestations of individual trait power, and taste preferences? Is there a relationship between dark side personality traits and taste preferences for foods and beverages? 


\begin{tabular}{|c|c|}
\hline Sagioglou \& Greitemeyer (2016) & $\begin{array}{l}\text { Bitter taste preferences associated with greater Psychopathy, Narcissism, Machiavellianism } \\
\text { and Sadism. Sour taste preferences are associated with greater Sadism. Salty taste } \\
\text { preferences are associated with lower Sadism. }\end{array}$ \\
\hline Ufer, Lin \& Ortega (2019) & $\begin{array}{l}\text { Extraversion and Conscientiousness increases, and agency decreases, willingness to pay for } \\
\text { cooperative-grown coffee }\end{array}$ \\
\hline $\begin{array}{l}\text { Lara, Antoniolli, Frozi, Schneider \& Ottoni } \\
\text { (2011) }\end{array}$ & $\begin{array}{l}\text { Coffee intake is moderately related to personality traits (reward dependence).Tea } \\
\text { consumption is associated with more mature and adaptive traits (harm avoidance, } \\
\text { persistence). Coca Cola drink consumption and smoking is associated with more immature } \\
\text { and maladaptive personality profiles (novelty seeking) }\end{array}$ \\
\hline Mihaela \& Bianca (2018) & $\begin{array}{l}\text { Sensory liking for sweet and fat foods is negatively associated with histrionic personality } \\
\text { traits }\end{array}$ \\
\hline $\begin{array}{l}\text { Bedwell, Spencer, Chirino \& O-Donnell } \\
\text { (2019) }\end{array}$ & $\begin{array}{l}\text { No Big Five personality factors were found to be related to hedonic ratings of the Sweet } \\
\text { Taste Test (STT). } \\
\text { Hedonic slope was larger for those high in Flight-Feeze-Avoidance System }\end{array}$ \\
\hline $\begin{array}{l}\text { Sena-Esteves, Mota \& Malfeito-Ferreira } \\
\text { (2018) }\end{array}$ & $\begin{array}{l}\text { Those low in Extraversion preferred a sweeter sample of wine. Female novices preferred } \\
\text { sweeter wine samples when compared to experienced male consumers }\end{array}$ \\
\hline Samant \& Seo (2018) & Extraversion and Neuroticism modulate predicitions of liking and preference of tastes \\
\hline $\begin{array}{l}\text { Harmon, Gauvain, Reisz, Arthur \& Story } \\
\text { (2018) }\end{array}$ & $\begin{array}{l}\text { Openness to experience and Neuroticism predicts water preference.The positive relationship } \\
\text { with Openess was moderated by gender; females preferred bottled water }\end{array}$ \\
\hline Waymire (2017) & $\begin{array}{l}\text { Replication of Sagioglou \& Greitemeyer's } 2016 \text { study. } \\
\text { Failed to support link between psychopathy and bitter taste preference. Negative correlation } \\
\text { between Extraversion and perceived sucrose intensity, and Agreeableness and perceived } \\
\text { quinine intensity }\end{array}$ \\
\hline Higgins, Bakke \& Hayes (2020) & Liking and intake of pale ales positiviely related to sensation seeking. \\
\hline Ardebili \& Rickertson (2020) & $\begin{array}{l}\text { Personality influences preference for GM soybean oil, salmon and GM-fed salmon. } \\
\text { Conscientiousness reduced, and Agreeableness increased, aversion toward GM-fed and GM } \\
\text { salmon. }\end{array}$ \\
\hline Elfhag \& Erlanson-Albertsson (2006) & Strong sweet taste preference associated with neuroticism, particularly lack of assertiveness. \\
\hline
\end{tabular}

Table 1 Literature review of studies investigating personality traits and taste preferences

\section{Method}

\section{Participants}

The participant sample was composed of 120 females and 78 males; mean age $42.27(S D=13.90) ; 168$ participants indicated their ethnicity as 'White', 12 as 'Black', and 14 people indicated they were 'Other/ Not Specified'.

\section{Taste Preference measures}

Participants were asked "Which of the following foods, drinks and condiments do you like the taste of?", and were presented with 5 items for each of the tastes: sweet, sour, bitter and salty (Meier et al., 2012). They then indicated their liking for the item presented on 6 point liking likert scale, of 1 'Dislike Strongly' to 6 'Like Strongly'. Cronbach's alpha values were .695 for Sweet taste items, .713 for Sour, .614 for Bitter, and .569 for Salty. A preference for spice was measured using Brynes \& Hayes (2013) questionnaire (Cronbach's Alpha score of .907) for the statement items used. They were also asked "Which of the following types of chocolate do you enjoy the taste of?", presented with items of 'Dark Chocolate (35\% Cocoa)' and 'Milk Chocolate (10\%

Cocoa)'; based on the distinctions outlined by Andrews (2009).

We also included a scale measure of general preference for coffee strength, from zero (preference for weaker coffee) to 30 (preference for stronger coffee). Alcohol preference was measured on a scale measure of general preference for alcohol strength in common beverages, from zero (weak alcohol strength preference) to 12 (strong alcohol strength preference.

\section{Personality measures}

1. Personal Sense of Power: this comprised of 8 statements relating to participants' self-reported power in their relationships (Anderson, John \& Keltner, 2012). Cronbach's Alpha was .920 for the 8 items.

2. A Sexual Dominance (Sanchez, Phelan, Moss-Racusin \& Good, 2012) and Sexual Submissiveness scale (Sanchez, Kiefer \& Ybarra, 2006). Cronbach's Alpha was .892 and .852 for the items of sexual dominance and submissiveness respectively.

3. Promotion Orientation comprising of 7 items was employed (Hamstra, Sassenberg, Van Yperen \& Wisse, 2014). Cronbach's Alpha was .782.

4. The Dark Triad was measured using the Dirty Dozen questionnaire (Jonason \& Webster, 2010) which had three overall scores of Machiavellianism, Psychopathy and Narcissism. Cronbach's Alpha was .881, .772 and .865; for Machiavellianism, Psychopathy and Narcissism, respectively.

5. Dark Tetrad trait of everyday Sadism was assessed using the Short Sadistic Impulse Scale (SSIS; O’Meara, Davies \& Hammond, 2011). The Cronbach's Alpha was .861. 


\section{Procedure}

Amazon Mechanical Turk (MTurk) is an online platform commonly used in psychological research to recruit participants (Buhrmester, Kwang \& Gosling, 2011). Ethics permission was sought and granted (CEHP/514/2017)

\section{Results}

\section{Preliminary Analyses}

The basic data is shown in Table 2. Sweet taste preferences were negatively correlated with everyday Sadism, $r=-.230, p<.01$, and Psychopathy, $r=-.197, p<.01$. Sour taste preferences were not correlated with any personality measures. Bitter taste preferences were positively correlated with promotion regulatory focus, $r=.151$. Salty taste preferences were positively correlated with promotion regulatory focus, $r=.158$, and negatively correlated with Psychopathy, $r=-.172$. Spice sensation preference was positively correlated with personal sense of power, $r=.196$, promotion regulatory focus, $r=.275$, and Narcissism, $r=.185$.

Dark chocolate preference was positively correlated with personal sense of power, $r=.180$. Milk chocolate preference was negatively correlated with everyday Sadism, $r=-.297$, and Psychopathy, $r=-.216$. Coffee strength preference was positively correlated with promotion regulatory focus, $r=.178$. Lastly, alcohol strength preference was positively correlated with personal sense of power, $r=.202$, promotion regulatory focus, $r=.217$, sexual dominance, $r=.214$, Machiavellianism, $r=.161$ and Narcissism, $r=.237$.

\begin{tabular}{|c|c|c|c|c|c|c|c|c|c|c|c|c|c|c|c|c|c|c|c|}
\hline Variables & Means & $S D$ & 1 & 2 & 3 & 4 & 5 & 6 & 7 & 8 & 9 & 10 & 11 & 12 & 13 & 14 & 15 & 16 & \\
\hline 1. Sweet taste preference & 23.6 & 4.41 & & & & & & & & & & & & & & & & & \\
\hline 2. Sour taste preference & 15.78 & 5.44 & $.221 * *$ & & & & & & & & & & & & & & & & \\
\hline 3. Bitter taste preference & 15.18 & 5.36 & 0.101 & $\begin{array}{l}.590 \\
* *\end{array}$ & & & & & & & & & & & & & & & \\
\hline 4. Salty taste preference & 20.03 & 4.84 & $.484^{* *}$ & $\begin{array}{l}.237 \\
* *\end{array}$ & $.333 * *$ & & & & & & & & & & & & & & \\
\hline 5. Spice sensation preference & 4.43 & 2.03 & 0.02 & $\begin{array}{l}.279 \\
* *\end{array}$ & $.376^{* *}$ & $\begin{array}{l}.262 \\
* *\end{array}$ & & & & & & & & & & & & & \\
\hline 6. Dark chocolate preference & 5.91 & 1.35 & 0.106 & $\begin{array}{l}.259 \\
* *\end{array}$ & $.249 * *$ & 0.032 & $.168^{*}$ & & & & & & & & & & & & \\
\hline 7. Milk chocolate preference & 12.7 & 6.04 & $.264 * *$ & 0.02 & $-.159 *$ & 0.032 & $\begin{array}{r}-0.09 \\
6\end{array}$ & $\begin{array}{l}-.160 \\
*\end{array}$ & & & & & & & & & & & \\
\hline 8. Coffee strength preference & 12.38 & $\begin{array}{r}11.0 \\
2\end{array}$ & 0.029 & $\begin{array}{l}.226 \\
* *\end{array}$ & $.398^{* *}$ & $\begin{array}{l}0.156 \\
*\end{array}$ & $\begin{array}{l}.279 \\
* *\end{array}$ & 0.122 & -0.058 & & & & & & & & & & \\
\hline $\begin{array}{l}\text { 9. Alcohol strength } \\
\text { preference }\end{array}$ & 5.72 & 3.95 & -0.04 & 0.049 & $.335 * *$ & 0.120 & $\begin{array}{l}.315 \\
* *\end{array}$ & 0.079 & 0.003 & $\begin{array}{l}.234 \\
* *\end{array}$ & & & & & & & & & \\
\hline 10. Personal Sense of Power & 38.39 & 10.2 & 0.089 & 0.123 & 0.075 & 0.061 & $\begin{array}{l}.196 \\
* *\end{array}$ & $.180^{*}$ & 0.107 & $\begin{array}{r}-0.02 \\
1\end{array}$ & $\begin{array}{l}.202 \\
* *\end{array}$ & & & & & & & & \\
\hline $\begin{array}{l}\text { 11. Promotion Regulatory } \\
\text { Focus }\end{array}$ & 13.45 & 4.15 & 0.139 & 0.130 & $* 0.151$ & $\begin{array}{l}0.158 \\
*\end{array}$ & $\begin{array}{l}.275 \\
* *\end{array}$ & 0.115 & 0.045 & $\begin{array}{l}0.178 \\
*\end{array}$ & $\begin{array}{l}.217 \\
* *\end{array}$ & $\begin{array}{l}.239 \\
* *\end{array}$ & & & & & & & \\
\hline 12. Sexual Dominance & 17.74 & $\begin{array}{r}11.0 \\
1\end{array}$ & -0.068 & $\begin{array}{r}-0.08 \\
6\end{array}$ & -0.059 & 0.011 & .070 & $\begin{array}{r}-0.09 \\
7\end{array}$ & 0.041 & 0.068 & $\begin{array}{l}.214 \\
* *\end{array}$ & 0.106 & 0.081 & & & & & & \\
\hline 13. Sexual Submissiveness & 11.06 & 7.06 & 0.028 & $\begin{array}{r}-0.05 \\
2\end{array}$ & -0.073 & 0.036 & .056 & $\begin{array}{r}-0.09 \\
7\end{array}$ & 0.018 & 0.088 & 0.120 & $\begin{array}{r}-0.13 \\
2\end{array}$ & $\begin{array}{l}-.145 \\
*\end{array}$ & .289 & & & & & \\
\hline 14. Everyday Sadism & 9.1 & 5.93 & $\begin{array}{l}-.230 \\
* *\end{array}$ & $\begin{array}{r}-0.01 \\
9\end{array}$ & 0.080 & -0.125 & .093 & $\begin{array}{r}-0.07 \\
2\end{array}$ & $\begin{array}{l}-0.297 \\
* *\end{array}$ & 0.074 & 0.044 & $\begin{array}{r}-0.13 \\
6\end{array}$ & 0.037 & 0.035 & 0.008 & & & & \\
\hline 15. Machiavellianism & 14.19 & 7.96 & -0.097 & $\begin{array}{r}-0.01 \\
7\end{array}$ & 0.063 & -0.045 & 0.12 & $\begin{array}{r}-0.06 \\
6\end{array}$ & -0.125 & 0.084 & $\begin{array}{l}0.161 \\
*\end{array}$ & 0.083 & 0.115 & $.162^{*}$ & 0.125 & $\begin{array}{l}0.455 \\
* *\end{array}$ & & & \\
\hline 16. Psychopathy & 13.52 & 5.34 & $\begin{array}{l}-.197 \\
* *\end{array}$ & 0.085 & 0.127 & $-.172^{*}$ & 0.073 & $\begin{array}{r}-0.03 \\
7\end{array}$ & $-.216^{* *}$ & 0.132 & 0.134 & $\begin{array}{r}-0.08 \\
3\end{array}$ & 0.089 & 0.091 & $\begin{array}{l}0.155 \\
*\end{array}$ & $\begin{array}{l}0.511 \\
* *\end{array}$ & $\begin{array}{l}0.686 \\
* *\end{array}$ & & \\
\hline 17. Narcissism & 15.09 & 6.2 & 0.046 & 0.061 & 0.112 & 0.004 & .185 & $\begin{array}{r}-0.01 \\
3\end{array}$ & 0.068 & 0.051 & $\begin{array}{l}.237 \\
* *\end{array}$ & $\begin{array}{l}.265 \\
* *\end{array}$ & $\begin{array}{l}.272 \\
* *\end{array}$ & 0.092 & $\begin{array}{r}-0.04 \\
8\end{array}$ & $0.172^{*}$ & $\begin{array}{l}0.520 \\
* *\end{array}$ & $\begin{array}{l}0.339 \\
* *\end{array}$ & \\
\hline
\end{tabular}

Table 2 Bivariate correlations between variables

\section{Step-wise regression}

Taste preferences were independently analysed through a series of stepwise regressions controlling for age, gender and ethnicity. Unlike Sagioglou and Greitemeyer (2016), we have treated personality characteristics as predictors of the taste preferences of interest as the former are more stable than the latter. The demographic variables were controlled as prior research suggests these factors influence taste preferences. Ethnicity was categorised as either 'White', 'Black' or 'Other', and these were treated as dummy variables.
The final stage of the step-wise regressions performed for each of our taste preference measures is summarized in Table 3. For the step-wise regression of sweet taste preference, Psychopathy was not included as a significant predictor despite an initial negative correlation with sweet taste preference. The resulting model explained $7.6 \%$ of the variance for sweet taste preferences, $F(6,191)=3.682$, using promotion regulatory focus, beta $=.149$, , everyday Sadism, beta $=-.204$, and ethnicity (other), beta $=-.223$, as the most significant predictor variables. 


\begin{tabular}{|c|c|c|c|c|}
\hline \multirow[t]{4}{*}{ Variables entered } & \multicolumn{3}{|c|}{ Dependent Variables } & \\
\hline & \multicolumn{3}{|c|}{ Sweet Taste preference } & \\
\hline & $F(6,191)$ & Adj. $R^{2}$ & $\beta$ & $t^{t}$ \\
\hline & $3.682 *$ & .076 & & \\
\hline Promotion Regulatory Focus & & & $.149 *$ & 2.159 \\
\hline Everyday Sadism & & & $-.204^{* *}$ & -2.831 \\
\hline \multirow[t]{4}{*}{ Ethnicity (Other) } & & & $-.223 * *$ & -2.096 \\
\hline & \multicolumn{3}{|c|}{ Bitter Taste Preference } & \\
\hline & $F(5,192)$ & Adj. $R^{z}$ & $\beta$ & $t^{t}$ \\
\hline & $5.557^{* * *}$ & .104 & & \\
\hline Promotion Regulatory Focus & & & $.152 *$ & 2.236 \\
\hline Age & & & $.208^{* *}$ & 3.001 \\
\hline \multirow[t]{4}{*}{ Gender } & & & $-.184 *$ & -2.668 \\
\hline & \multicolumn{3}{|c|}{ Salty Taste Preference } & \\
\hline & $F(7,190)$ & Adj. $R^{z}$ & $\beta$ & $t^{t}$ \\
\hline & $4.089 * * *$ & .099 & & \\
\hline Promotion Regulatory Focus & & & $.210^{* * *}$ & 3.018 \\
\hline Psychopathy & & & $-.231 * * *$ & -3.229 \\
\hline Sexual Submissiveness & & & $.200 *$ & 2.649 \\
\hline \multirow[t]{4}{*}{ Gender } & & & $-.237 * *$ & -3.187 \\
\hline & \multicolumn{3}{|c|}{ Spice Sensation Preference } & \\
\hline & $F(7,190)$ & Adj. $R^{2}$ & $\beta$ & $t$ \\
\hline & $4.121 * * *$ & .100 & & \\
\hline Promotion Regulatory Focus & & & $.253^{* * *}$ & 3.568 \\
\hline Personal Sense of Power & & & $.171^{*}$ & 2.381 \\
\hline Sexual Submissiveness & & & $.162^{*}$ & 2.191 \\
\hline \multirow[t]{4}{*}{ Gender } & & & $-.169^{*}$ & -2.310 \\
\hline & \multicolumn{3}{|c|}{ Dark Chocolate Preference } & \\
\hline & $F(5,192)$ & Adj. $R^{z}$ & $\beta$ & $t$ \\
\hline & $4.989 * * *$ & .092 & & \\
\hline Personal Sense of Power & & & $.152^{*}$ & 2.199 \\
\hline \multirow[t]{4}{*}{ Age } & & & $.164^{*}$ & 2.345 \\
\hline & \multicolumn{3}{|c|}{ Milk Chocolate Preference } & \\
\hline & $F(5,192)$ & Adj. $R^{2}$ & $\beta$ & $t^{t}$ \\
\hline & $4.275 * * *$ & .077 & & \\
\hline \multirow[t]{4}{*}{ Sadism } & & & $-.310^{* * *}$ & -4.314 \\
\hline & \multicolumn{3}{|c|}{ Coffee Strength Preference } & \\
\hline & $F(6,191)$ & Adj. $R^{2}$ & $\beta$ & $t^{t}$ \\
\hline & $3.350^{* *}$ & .067 & & \\
\hline Promotion Regulatory Focus & & & $.204^{*}$ & 2.901 \\
\hline Sexual Submissiveness & & & $.188^{*}$ & 2.502 \\
\hline \multirow[t]{4}{*}{ Gender } & & & $-.234^{*}$ & -3.149 \\
\hline & \multicolumn{3}{|c|}{ Alcohol Strength Preference } & \\
\hline & $F(7,190)$ & Adj. $R^{2}$ & $\beta$ & $t$ \\
\hline & $4.121 * * *$ & .100 & & \\
\hline Promotion Regulatory Focus & & & $.161^{*}$ & 2.259 \\
\hline Narcissism & & & $.190^{*}$ & 2.650 \\
\hline Sexual Dominance & & & $.183^{*}$ & 2.661 \\
\hline$\star * * p<.001 * * p<.01 * p$ & & & & \\
\hline
\end{tabular}


The step-wise regression of bitter taste preference the resulting model explained $10.4 \%$ of the variance, $F(5,192)=5.557$, using promotion regulatory focus, $\beta=.15, p<.05$, Age, $\beta=.21$, and gender, $\beta=-.18$, as the most significant predictor variables.

The results for the salty taste preference,showed sexual submissiveness was included as a significant predictor despite no initial correlation with sweet taste preference. The resulting model explained $9.9 \%$ of the variance for salty taste preferences, $F(7,190)=4.089$, using promotion regulatory focus, $\beta=.21$, Psychopathy, $\beta=-.23$, sexual submissiveness, $\beta=.20$, and gender, $\beta=-.24$, as the most significant predictor variables.

The results for spice sensation preference, showed Narcissism was not included as a significant predictor despite an initial positive correlation with spice taste preference, whereas sexual submissiveness was included despite no initial correlation. The resulting model explained $10 \%$ of the variance for spice sensation preferences, $F(7,190)=4.121$, using promotion regulatory focus, $\beta=.25$, personal sense of power, $\beta=.17$, sexual submissiveness, $\beta=.16$, and gender, $\beta=-.17$, as the most significant predictor variables.

The results for dark chocolate preference explained $9.2 \%$ of the variance, $F(5,192)=4.989$, using personal sense of power, $\beta=.15$, and age, $\beta=.16$, as the most significant predictor variables. The results for milk chocolate preference, explained $7.7 \%$ of the variance, $F(5,192)=$ 4.275 , using everyday Sadism, $\beta=-.31$, as the only significant predictor variable.

The results for coffee strength preference, explained $6.7 \%$ of the variance $F(6,191)=3.350$, using promotion regulatory focus, $\beta=.20$, sexual submissiveness, $\beta=.19$, and gender, $\beta=-.23$, as the most significant predictor variables. The results for alcohol strength preference, explained $10 \%$ of the variance for coffee strength preference, $F(7,190)=4.121$, using promotion regulatory focus, $\beta=.16$, Narcissism, $\beta=.19$, and sexual dominance, $\beta=.18$ as the most significant predictor variables.

\section{Discussion}

Like other studies our results do not support some of the findings of Sagrioglou and Greitemeyer (2016), as we found no significant associations between sour taste preferences and any personality traits. Bitter taste preferences were found not to significantly correlate with dark side traits and everyday Sadism. Instead, our results found that bitter taste preferences were associated with promotion regulatory focus. This is unexpected, as previous literature suggests that individuals with a promotion orientation of regulatory focus should be sensation-seeking and harm-avoiding (Higgins, 1987); and as bitter tastes are naturally aversive (Desor, Maller \& Andrews, 1975).

The associations between age and bitter taste preferences may offer some explanation for this novel finding, as with greater exposure to certain food and drink stimuli we develop an acquired taste for initially noxious and unpleasant stimuli (Higgs, 2015). In this sense you acquire a sense of taste. In some cultures and societies initially naturally repugnant tastes from bitter food and drinks may become more enjoyable and palatable with age, and as such may be sought out by individuals with a greater sensation seeking promotion regulatory focus. This is famous with the Marmite which is a sticky, dark brown paste with a highly distinctive, salty, flavour that polarises opinion such that it is used in conversation to suggest biplor opinions: you love it or hate it.

Promotion regulatory focus was positively associated with sweet taste preferences, while everyday Sadism was negatively associated. These results are not consistent with prior research suggested a negative correlation between sweet taste preferences and power. However, the association between sweet taste preferences and promotion regulatory focus is consistent with the notion that individuals with a promotion orientation will seek out hedonistic sensations, as sweet tastes are naturally attractive due to the evolutionary benefit of consuming foods high in sugar (Desor et al., 1975). Furthermore, as sadism is by definition is the preference for aversive stimuli, it is not unsurprising to observe that individuals with greater trait sadism had a lower preference for sweet tastes.

Salty taste preferences were positively associated with promotion regulatory focus and sexual submissiveness. Like sweet tastes, salty tastes are naturally attractive due to presence of sodium chloride, and essential compound for metabolism (Bradbury, 2004). The positive association between salty taste preferences and sexual submissiveness is novel, and merits replication and extension. The negative association between psychopathy and salty taste preferences is somewhat unexpected, although Sagioglou and Greitemeyer did find negative associations between salty taste preferences and malevolent personality traits, most notably everyday Sadism (2016).

The association between spice sensation preference and promotion regulatory focus supports previous research findings that sensationseeking individuals enjoy spice sensation and spicy food items (Byrnes $\&$ Hayes, 2013). Furthermore, the positive association of spice sensation preference with personal sense of power and gender is may be due to impression management by men as it has been suggested that females are attracted to males who exhibit preferences for potentially harmful food types as this signals a strong immune system (Al-Shawaf, Lewis, Alley \& Buss, 2015). Interestingly, spice sensation also displayed a positive relationship with sexual submissiveness, for which there is no previous literature to provide an explanation.

Dark chocolate preferences were found to be positively associated with personal sense of power and age. Previous research has suggested that milk chocolate varieties are preferred by individuals with lower power and greater disinhibition (Lattimore \& Maxwell, 2005).Thus stronger varieties of chocolate may be expected to be preferred by individuals with greater personal power. However we found milk chocolate preferences were not associated with lower personal sense of power, though it was strongly associated with lower Everyday Sadism, which supports our previous finding of sweet taste preference being negatively correlated with Sadism.

Coffee strength preferences have being reported to be positively correlated with sensation-seeking in individuals (Mattes, 1984), and thus it is unsurprising that we find a similar positive correlation with promotion regulatory focus.

Alcohol strength preferences have also been found to positively correlate with sensation seeking in individuals, but also dark side traits (Magid, MacLean \& Colder, 2007). The correlations between coffee strength preference with promotion regulatory focus and Narcissism support prior research findings. Interestingly, a strong correlation was also observed with sexual dominance.

Promotion orientation of regulatory focus was a personality predictor for the most taste preferences. This suggests that sensation seeking and harm avoidance may be the influential aspects of personality correlated with taste, and other measures of trait sensation seeking should be used in future research to elaborate the possible relationships with taste preferences. The findings that sexual submissiveness and sexual dominance exhibited relationships with a variety of taste preferences is entirely novel.

Like all studies this small, expoloratory, cross-sectional, self-report study had limitations. It would have been desirable to have a larger 
population and to know more about the eating habits and history as well dara on other personality factors. This study was essentially exploratory and picked up on the rapidly expanding dark-side literature (Furnham, 2021). It was stimulated by the idea that certain taste preferences may be indicators of psychopathology. However for this field to move forward it needs some theoretical foundations to test: namely how people with certain dispositions may be attracted to eating particular foods for the physiologival effects they have (like alcohol, coffee) or the impressions they many create (like spicy food). It would also be important to understand their history of the consumption of certain foods, as well as the quantity and corcumstances in which they are consumed.

\section{Data Availability:}

This is obtainable from the first author upon request.

\section{Registration:}

This paper was not pre-registered with the journal.

\section{Ethics:}

This was sought and obtained (CEHP/514/2017).

\section{Informed Consent:}

Participants gave consent for their anonymised data to be analysed and published.

\section{Conflict of interest}

There is no conflict of interest.

\section{Acknowledgement:}

I would like to acknowledge the help of Marcus Gee, Zohra Ohsan, Charlotte Robinson and Laura Weis in the data collection and analysis.

\section{References}

1. Al-Shawaf, L., Lewis, D. M., Alley, T. R., \& Buss, D. M. (2015). Mating strategy, disgust, and food neophobia. Appetite, 85, 3035.

2. Anderson, C., John, O. P., \& Keltner, D. (2012). The personal sense of power. Journal of Personality, 80(2), 313-344.

3. Andrews, R. (2009). All about chocolate.

4. Ardebili, A. T., \& Rickertsen, K. (2020). Personality traits, knowledge, and consumer acceptance of genetically modified plant and animal products. Food Quality and Preference, 80, 103825 .

5. Asao, K., Luo, W., \& Herman, W. H. (2012). Reproducibility of the measurement of sweet taste preferences. Appetite, 59(3), 927-932.

6. Bartoshuk, L. M. (1991). Taste, smell and pleasure. In R. C. Bolles (Ed.), The hedonics of taste (p. 15-28). Hillsdale, NJ: Lawrence Erlbaum Associates, Inc.

7. Batra, R. K., Ghoshal, T., \& Raghunathan, R. (2017). You are what you eat: An empirical investigation of the relationship between spicy food and aggressive cognition. Journal of Experimental Social Psychology, 71, 42-48.

8. Bedwell, J. S., Spencer, C. C., Chirino, C. A., \& O'Donnell, J. P. (2019). The sweet taste test: relationships with anhedonia subtypes, personality traits, and menstrual cycle phases. Journal of Psychopathology and Behavioral Assessment, 41(2), 235-248.

9. Bègue, L., Bricout, V., Boudesseul, J., Shankland, R., \& Duke, A. A. (2015). Some like it hot: Testosterone predicts laboratory eating behavior of spicy food. Physiology \& Behavior, 139, 375377.
10. Bradbury, J. (2004). Taste perception: cracking the code. PLoS biology, 2(3), e64.

11. Buhrmester, M., Kwang, T., \& Gosling, S. D. (2011). Amazon's Mechanical Turk a new source of inexpensive, yet high-quality, data?. Perspectives on psychological science, 6(1), 3-5.

12. Byrnes, N. K., \& Hayes, J. E. (2013). Personality factors predict spicy food liking and intake. Food quality and preference, 28(1), 213-221.

13. Chabrol, H., Van Leeuwen, N., Rodgers, R., \& Séjourné, N. (2009). Contributions of psychopathic, narcissistic, Machiavellian, and sadistic personality traits to juvenile delinquency. Personality and Individual Differences, 47(7), 734739.

14. Cooke, L. J., \& Wardle, J. (2005). Age and gender differences in children's food preferences. British Journal of Nutrition, 93(5), 741-746.

15. Costa, P. T., \& McCrae, R. R. (1988). Personality in adulthood: a six-year longitudinal study of self-reports and spouse ratings on the NEO Personality Inventory. Journal of Personality and Social Psychology, 54(5), 853-863.

16. Desor, J. A., Maller, O., \& Andrews, K. (1975). Ingestive responses of human newborns to salty, sour, and bitter stimuli. Journal of Comparative and Physiological Psychology, 89(8), 966-970.

17. Dholakia, U. M., Gopinath, M., Bagozzi, R. P., \& Nataraajan, R. (2006). The role of regulatory focus in the experience and selfcontrol of desire for temptations. Journal of Consumer Psychology, 16(2), 163-175.

18. Drewnowski, A. (1997). Taste preferences and food intake. Annual Review of Nutrition, 17(1), 237-253.

19. Elfhag, K., \& Erlanson-Albertsson, C. (2006). Sweet and fat taste preference in obesity have different associations with personality and eating behavior. Physiology \& Behavior, 88(12), 61-66.

20. Eskine, K. J., Kacinik, N. A., \& Prinz, J. J. (2011). A bad taste in the mouth: Gustatory disgust influences moral judgment. Psychological Science, 22(3), 295-299.

21. Esposito, C.M., Ceresa, A., \& Buoli, M. (2021). The Association Between Personality Traits and Dietary Choices: A Systematic Review. Advances in Nutrition, nmaa166.

22. Furnham, A. (2008). Personality and Intelligence at Work. London: Routledge.

23. Furnham, A. (2021). The Bright and Dark Side of Personality: The relationship between Personality Traits and Personality Disorders. In: Lusk, D. \& Hayes, T. (Eds). The Good, the Bad, and the Human Dark Side at Work: New York: SIOP

24. Glanz, K., Basil, M., Maibach, E., Goldberg, J., \& Snyder, D. A. N. (1998). Why Americans eat what they do: taste, nutrition, cost, convenience, and weight control concerns as influences on food consumption. Journal of the American Dietetic Association, 98(10), 1118-1126.

25. Harmon, D., Gauvain, M., Reisz, Z., Arthur, I., \& Story, S. D. (2018). Preference for tap, bottled, and recycled water: Relations to PTC taste sensitivity and personality. Appetite, 121, 119-128.

26. Haynes, C., Lee, M. D., \& Yeomans, M. R. (2003). Interactive effects of stress, dietary restraint, and disinhibition on appetite. Eating behaviors, 4(4), 369-383.

27. Higgins, E. T. (1997). Beyond pleasure and pain. American Psychologist, 52(12), 1280-1300.

28. Higgins, M. J., Bakke, A. J., \& Hayes, J. E. (2020). Personality traits and bitterness perception influence the liking and intake of pale ale style beers. Food Quality and Preference, 86, 103994.

29. Higgs, S. (2015). Social norms and their influence on eating behaviours. Appetite, 86, 38-44. 
30. Hirschberger, G., \& Ein-Dor, T. (2005). Does a candy a day keep the death thoughts away? The terror management function of eating. Basic and Applied Social Psychology, 27(2), 179-186.

31. Hmieleski, K. M., \& Baron, R. A. (2008). Regulatory focus and new venture performance: A study of entrepreneurial opportunity exploitation under conditions of risk versus uncertainty. Strategic Entrepreneurship Journal, 2(4), 285-299.

32. Idson, L. C., Liberman, N., \& Higgins, E. T. (2000). Distinguishing gains from nonlosses and losses from nongains: A regulatory focus perspective on hedonic intensity. Journal of Experimental Social Psychology, 36(3), 252-274.

33. Jonason, P. K., \& Webster, G. D. (2010). The dirty dozen: a concise measure of the dark triad. Psychological Assessment, 22(2), 420-432.

34. Keller, C., \& Siegrist, M. (2015). Does personality influence eating styles and food choices? Direct and indirect effects. Appetite, 84, 128-138.

35. Kikuchi, Y., \& Watanabe, S. (2000). Personality and dietary habits. Journal of Epidemiology, 10(3), 191-198.

36. Lara, D. R., Antoniolli, E., Frozi, J., Schneider, R., \& Ottoni, G. L. (2011). Distinct personality traits associated with intake of coffee, tea, and cola drinks and smoking. Journal of Caffeine Research, 1(2), 101-108.

37. Lattimore, P., \& Maxwell, L. (2004). Cognitive load, stress, and disinhibited eating. Eating Behaviors, 5(4), 315-324.

38. Mahmut, M.K., \& Banzer, B. (2020). Exploring the Relationship Between Psychopathy and Taste Perception. Chemical Perceptions.

39. Magid, V., MacLean, M. G., \& Colder, C. R. (2007). Differentiating between sensation seeking and impulsivity through their mediated relations with alcohol use and problems. Addictive Behaviors, 32(10), 2046-2061.

40. Mattes, R. D. (1994). Influences on acceptance of bitter foods and beverages. Physiology \& Behavior, 56(6), 1229-1236.

41. Meier, B. P., Moeller, S. K., Riemer-Peltz, M., \& Robinson, M. D. (2012). Sweet taste preferences and experiences predict prosocial inferences, personalities, and behaviors. Journal of Personality and Social Psychology, 102(1), 163-174.

42. Mihaela, P., \& Bianca, V. (2018). Sweetie, no sweets!. Understanding the association between histrionic personality style and taste preference. $5^{\text {th }}$ International SGEM Conference, Albena, Bulgaria.

43. O'Meara, A., Davies, J., \& Hammond, S. (2011). The psychometric properties and utility of the Short Sadistic Impulse Scale (SSIS). Psychological Assessment, 23(2), 523-531.

44. Paulhus, D. L., \& Williams, K. M. (2002). The dark triad of personality: Narcissism, Machiavellianism, and psychopathy. Journal of Research in Personality, 36(6), 556-563.

45. Petre, L. M., \& Vatasescu, B. (2018). Sweetie, No Sweets! Understanding The Association Between Histrionic Personality Style And Taste Preferences. In 5th Int. Mult. Sci. Con Soc Sci \& Arts SGEM (pp. 439-344).

46. Reed, D. R., Tanaka, T., \& McDaniel, A. H. (2006). Diverse tastes: Genetics of sweet and bitter perception. Physiology \& Behavior, 88(3), 215-226.
47. Rozin, P., Haidt, J., \& Fincher, K. (2009). From oral to moral. Science, 323(5918), 1179-1180.

48. Sagioglou, C., \& Greitemeyer, T. (2014). Bitter Taste Causes Hostility. Personality and Social Psychology Bulletin, 40(12), 1589-1597.

49. Sagioglou, C., \& Greitemeyer, T. (2016). Individual differences in bitter taste preferences are associated with antisocial personality traits. Appetite, 96, 299-308.

50. Saliba, A. J., Wragg, K., \& Richardson, P. (2009). Sweet taste preference and personality traits using a white wine. Food Quality and Preference, 20(8), 572-575.

51. Samant, S.S. \& Seo, H. (2019a). Using both emotional responses and sensory attribute intensities to predict consumer liking and preference toward vegetable juice products. Food Quality and Preference, 73, 75-85.

52. Samant, S. S., \& Seo, H. S. (2019b). Personality traits affect the influences of intensity perception and emotional responses on hedonic rating and preference rank toward basic taste solutions. Journal of Neuroscience Research, 97(3), 276-291.

53. Sariyska R, Markett, S, Lachmann, B. \& Montag, C. (2019) What Does Our Personality Say About Our Dietary Choices? Insights on the Associations Between Dietary Habits, Primary Emotional Systems and the Dark Triad of Personality. Frontiers in Psychology, 10, 2591.

54. Sena-Esteves, M. M., Mota, M., \& Malfeito-Ferreira, M. (2018). Patterns of sweetness preference in red wine according to consumer characterisation. Food Research International, 106, $38-44$.

55. Spence, C. (2017). Gastrophysics: the new science of eating. London: Viking Penguin.

56. Steiner, J. E., Glaser, D., Hawilo, M. E., \& Berridge, K. C. (2001). Comparative expression of hedonic impact: affective reactions to taste by human infants and other primates. Neuroscience \& Biobehavioral Reviews, 25(1), 53-74.

57. Ufer, D., Lin, W., \& Ortega, D. L. (2019). Personality traits and preferences for specialty coffee: Results from a coffee shop field experiment. Food Research International, 125, 108504.

58. Ulrich-Lai, Y. M., Christiansen, A. M., Ostrander, M. M., Jones, A. A., Jones, K. R., Choi, D. C., \& Herman, J. P. (2010). Pleasurable behaviors reduce stress via brain reward pathways. Proceedings of the National Academy of Sciences, 107(47), 20529-20534.

59. Vartanian, L. R. (2015). Impression management and food intake. Current directions in research. Appetite, 86, 74-80.

60. Verbeke, W., \& Poquiviqui López, G. (2005). Ethnic food attitudes and behaviour among Belgians and Hispanics living in Belgium. British Food Journal, 107(11), 823-840.

61. Waymire, L. A. (2017). Bitter taste preference and psychopathy: A partial replication of Sagioglou and Greitemeyer, 2016. Honours Program Thesis. 51.

62. Zushi, N., Ogawa, M., \& Ayabe-Kanamura, S. (2021). Fear Reduces Perceived Sweetness: Changes in the Perception of Taste Due to Emotional State. SAGE Open. 